\title{
Obeticholic Acid Protects Against Cholestatic Liver Injury Induced by Lithocholic Acid via Inhibiting Exogenous Cell Apoptosis
}

\section{Yangping Zhu}

China Pharmaceutical University

\section{Changling Wang}

China Pharmaceutical University

Jingyi Yu

China Pharmaceutical University

\section{Yingying Miao}

China Pharmaceutical University

\section{Yuanyuan Chai}

China Pharmaceutical University

\section{Zhenzhou Jiang ( $\sim$ beaglejiang@cpu.edu.cn )}

China Pharmaceutical University https://orcid.org/0000-0002-0420-0822

Qinwei Yu

China Pharmaceutical University

\section{Research}

Keywords: Cholestatic liver injury, Obeticholic acid, Lithocholic acid, Farnesoid X receptor, Exogenous cell apoptosis

Posted Date: December 9th, 2021

DOI: https://doi.org/10.21203/rs.3.rs-1116597/v1

License: (c) (1) This work is licensed under a Creative Commons Attribution 4.0 International License. Read Full License 


\section{Abstract}

Background: Lithocholic acid (LCA) is one kind of endogenous bile acids which is a typical index in primary biliary cholangitis (PBC). It could cause severe cholestatic liver injury in rodents. Obeticholic acid (OCA) is a major treatment for PBC. However, its effect and mechanism in LCA-induced liver injury was still unclear beside of bile acid regulation. This study aims to evaluate the hepatoprotective effect and mechanism of OCA against LCA-induced cholestatic liver injury.

Results: LCA-induced upregulations of ALT, AST, ALP and TBA were reduced and the bile acid profiles in serum, liver and bile were improved significantly by OCA. This bile acid regulating effect of OCA was mainly based on increasing the expression of bile acid efflux transporters bile salt export pump (BSEP), multidrug resistant associated protein 2 (MRP2), MRP3 and multi-drug resistance 3 (MDR3) instead of bile acid synthesis inhibition. Furthermore, it was found that OCA reduced the activation and expression of Caspase 8/3 signaling pathway without the change of $p-M L K L$ and BAX in LCA-induced cholestatic model. And the inhibition of Caspase 8/3 signaling pathway depended on the activation of Farnesoid $X$ receptor (FXR) to inhibit Caspase 8 cleavage to form a active complex.

Conclusions: This study found OCA improved LCA-induced cholestatic liver injury via FXR-induced exogenous cell apoptosis, which provided a new evidence for the application of OCA to ameliorate PBC in clinical.

\section{Introduction}

The imbalance of bile acid homeostasis including abnormal distribution accumulation would lead to a serious of liver disease including cholestasis[1,2]. Cholestasis is characterized by intrahepatic accumulation of potentially cytotoxic bile acids (BAs) subsequently leading to liver injury with disruption of hepatocellular integrity, inflammation, fibrosis and ultimately liver cirrhosis[3]. Thus, regulation of BAs metabolism has been recognized as a new strategy for the therapy of liver disease.

Primary BAs are deconjugated and converted by microflora to secondary bile acids including deoxycholic acid (DCA) and lithocholic acid (LCA) [4, 5]. In clinical, it was showed that cholestatic liver injury accompanied by plasma lithocholic acid (LCA) levels elevated generally[6]. Moreover, the cholestatic liver injury model, which was established by intraperitoneal injections of LCA could increase the level of serum Alanine Aminotransferase (ALT), Aspartate Aminotransferase (AST), Alkaline Phosphatase (ALP) and Total Bile Acid (TBA), even lead to inflammation in C57BL/ 6 mice, which is similar with the symptom of cholestatic liver injury in clinical[7]. Furthermore, it was demonstrated that LCA feeding in mice leads to segmental bile duct obstruction, destructive cholangitis, periductal fibrosis, and an adaptive transporter and metabolic enzyme response [8]. Meanwhile, it was reported that, apoptosis was decreased during CAR-mediated hepatoprotection against LCA-induced cholestasis[9]. These studies suggested antiapoptosis might be a promising strategy for the treatment of cholestasis. 
Obeticholic acid (OCA) was approved by Health Canada for the treatment of primary biliary cholangitis (PBC) in combination with ursodeoxycholic acid (UDCA) in adults with an inadequate response to UDCA or as monotherapy in adults unable to tolerate UDCA[10]. It is an agonist of Farnesoid X receptor (FXR) that plays an important role in the maintenance of bile acid homeostasis. OCA has shown good efficacy in various types of liver diseases in non-clinical studies[11-15]. Based on the activation of FXR, OCA could increase expression of bile acid efflux transporters and decrease expression of bile acid synthase and bile acid uptake transporters to improve BAs dysregulation[16]. Recent study has shown that the decrease of FXR could cause apoptotic signal transduction by isolating Caspase 8 to form the deathinducing signaling complex in hepatocyte[17]. Thus, as an agonist of FXR, it is valuable to investigate whether FXR-Caspase 8 axis play a role in the hepatoprotection of OCA against cholestatic liver injury.

This study aims to evaluate the hepatoprotective effect and mechanism of OCA against LCA-induced cholestatic liver injury. It investigated the role of FXR in OCA inhibiting apoptosis after LCA treatment in vivo and vitro. The results provided a new evidence to explain the anti-cholestatic effect of OCA in clinical.

\section{Results}

\section{Hepatoprotective effect of OCA on LCA-induced liver injury}

To explore the hepaprotective effect of OCA on LCA-induced cholestatic liver injury, mice were orally administered with LCA for 4 days with pretreatment of OCA. Pretreatment with $10 \mathrm{mg} / \mathrm{kg}$ and $20 \mathrm{mg} / \mathrm{kg}$ OCA could increase the food intake (Fig. 1a) and body weight (Fig. 1b) reduced by LCA. Meanwhile, the increase of liver weight index induced by LCA could also be improved by OCA (Fig. 1c). Besides, the raised ALT and AST in serum, the biochemical indicators of hepatocyte damage, were reduced by OCA (Fig. 1d, e). Similarly, serum ALP which is the biochemical indicator of biliary toxicity was also significantly reduced in OCA-treated mice (Fig. 1f). The H\&E results of the liver are shown in Fig. 1g, severe liver necrosis, diffuse vacuolization and slight inflammatory cell infiltration occurred in LCA group. Expectedly, OCA could alleviate these pathological changes efficaciously. The expressions of liver pro-inflammatory

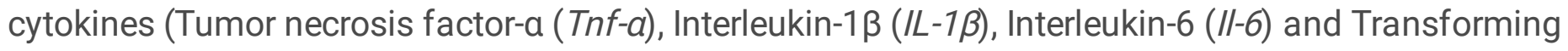
growth factor $\beta($ Tgf- $\beta)$ ) in LCA group were slightly increased, especially $11-6.20 \mathrm{mg} / \mathrm{kg} \mathrm{LCA+OCA} \mathrm{could}$ reduce the elevated all these four cytokines at gene level, in which $11-6$ could be reduced by $10 \mathrm{mg} / \mathrm{kg}$ OCA (Fig. 1h-k). These results suggested that OCA remarkably protected liver from LCA-induced injury.

\section{OCA improved LCA-induced cholestasis in mice}

After the administration of LCA, gallbladder became more swollen and heavier and liver showed white and enlarged, while OCA improved these changes significantly in both dosage (Fig. 2a, b). The TBA content in serum, liver and bile increased significantly in LCA group, which could also be reduced by OCA (Fig. 2c). It indicated that OCA could ameliorate LCA-induced cholestasis.

To further analyze the effect of OCA on bile acid profiles, the targeted metabolomics of BAs analysis was performed in serum, liver, bile and the content of intestine (including duodenum, jejunum, ileum, cecum 
and colon). After the treatment of LCA, the content of bile acids in serum, liver and bile were increased obviously while OCA could reduce the accumulation of bile acid in these bile pools (Fig. 2d-f). In all these contents of intestine, there was no obvious difference between control and LCA group. OCA could slightly increase the content of BAs in the content of jejunum, cecum and colon compared with LCA group (Fig. 2g-k). These results suggested the effect of OCA mainly occurred in liver instead of lleum.

According to principal component analysis (PCA), the bile acid profile of LCA group showed significant difference in serum, liver and bile (Fig. 3a, c, e). However, there is no difference of bile acid profile in duodenum, jejunum, ileum, cecum and colon (Fig. S1). Specifically, in serum, OCA decreased all kind of BAs increased by LCA (Fig. 3b). In liver, almost BAs were ascent after the treatment of LCA except $\beta$-MCA, $\omega$-MCA, CA and GCA, but OCA still decrease all kind of BAs (Fig. 3d). In bile, there were no significant increase of DCA, $\beta-M C A, C A, G C A$ and T- $\beta-M C A$ in LCA group (Fig. 3f). Therefore, we focus on liver as a target tissue in the further study.

\section{OCA reduced bile acid efflux transporters to resist LCA-induced cholestasis}

To explore the mechanism of OCA against LCA-induced bile acid disorders, the changes of FXR-related bile acid synthase, transporter, and metabolic enzymes were investigated in vivo and vitro. Firstly, the expressions of FXR and SHP which declined in LCA group were increased significantly in both gene and protein level after the treatment of OCA (Fig. 4a, b). And then, it was found that LCA led to obvious reduction of CYP7A1 and CYP8B1 which could be restored by OCA unexpectedly (Fig. 4c, d). The decreased bile acid transporters sodium taurocholate co-transporting polypeptide (NTCP), bile salt export pump (BSEP), multidrug resistance-associated protein 2 (MRP2), MRP3 and multi-drug resistance 3 (MDR3) were upregulated by OCA in gene and protein level, while organic anion transporting polypeptide 2 (OATP2) only changed in gene level (Fig. 4e, f). In addition, LCA caused down-regulation of bile acid metabolic enzymes such as Bacs, Baat, Cyp2b10, Cyp3a11, Gst1a1 and Ugt2a3 in gene level, which could be reversed by OCA (Fig. S2a-f).

To further investigate the mechanism of OCA against LCA-induced hepatotoxicity, LCA-stimulated hepatocyte model was established in AML12 cell. The result showed that, after the pre-treatment of OCA, LCA could not decline the expression of FXR and SHP in hepatocyte. As a result, CYP7A1, CYP8B1, NTCP, BSEP, MRP2, MRP3 and MDR3 were also not reduced by LCA which is similar with the result in mice (Fig. 5a-c). It indicated that OCA up-regulated FXR resulting in the increase expression of bile acid efflux transporter BSEP, MRP2, MRP3 and MDR3 to improve the LCA-induced cholestasis.

\section{OCA inhibited LCA-induced hepatocyte exogenous apoptosis}

Apoptosis played important roles in lithocholic acid-induced cholestatic liver injury[18]. Necroptosis is triggered in PBC patients and mediates hepatic necroinflammation in BDL-induced acute cholestasis[19]. Therefore, the effects OCA on apoptosis and necroptosis were investigated. The results of TUNEL staining showed, OCA could inhibit LCA-induced apoptosis (Fig. 6a) and decreased the activity of Caspase 3 which raised by LCA in liver (Fig. 6b). Compare to LCA group, the protein expression of cleaved 
Caspase-3, cleaved Caspase-8 and cleaved PARP levels were reduced obviously after the treatment of OCA. However, there is no difference of BAX among the groups (Fig. 6c). These results indicated that LCA induced exogenous cell apoptosis while OCA had the efficacy to inhibit this pathway. Meanwhile, according to IHC (Fig. 6d) and protein expression of p-MLKL (Fig. 6e), we found that LCA and OCA had no effect on $p-M L K L$ which indicated LCA induced hepatocytotoxicity only via activating exogenous apoptosis pathway.

\section{OCA activated FXR to inhibit Caspase 8 cleavage in LCA-induced cholestatic liver injury}

To confirm the role of FXR in OCA reversing LCA-induced apoptosis, we used FXR interpreting model in vitro and vivo. First, the hepatotoxicity of LCA should be confirmed in the beginning. $60 \mu \mathrm{M}$ LCA could significantly decrease the cell viability of AML-12 after $24 \mathrm{~h}$ treatment. The pre-administration of $10 \mu \mathrm{M}$ OCA for $12 \mathrm{~h}$ had a protective effect on hepatotoxicity caused by LCA (Fig. 7a, b). Therefore, $10 \mu \mathrm{M}$ pretreatment for $12 \mathrm{~h}$ and $60 \mu \mathrm{M}$ LCA treatment for $24 \mathrm{~h}$ was selected for the following study.

Compared to the LCA group, OCA could down-regulate the expression of cleaved Caspase-3, cleaved Caspase-8 and cleaved PARP in AML-12 obviously (Fig. 7c). In FXr ${ }^{\Delta L}$ model, LCA could not cause an ascent of liver weight index as $F X r^{f / f l}$ mice (Fig. 8a). Meanwhile, ALT, AST and ALP had no change as well (Fig. 8b-d). The result in pathology showed no more inflammation and necrosis in liver after the treatment of LCA (Fig. 8e). On the other hand, OCA also did not perform a hepatoprotection as that in $F x f^{f / f l}$ mice (Fig. 8a-e). It indicated that OCA reversed LCA-induced exogenous apoptosis based on the activation of FXR.

\section{Discussion}

LCA is a hydrophobic secondary bile acid, which is mainly converted from CDCA by intestinal bacteria[20]. In rodents, LCA could interrupted bile flow to accumulate BAs in serum, liver and bile duct causing damage to hepatocytes, which was confirmed in this study (Fig. 2c-f). Because the similarity with the symptoms in clinical, LCA-treated rodents are always used as cholestatic models[21]. It was found that the elevations of ALT and AST were more significant than ALP (Fig. 1d-f), which indicated LCAinduced more severe damage to liver except bile flow block. Furthermore, the results from pathology and the mRNA of inflammatory factor (Fig. 1g-k) confirmed this opinion which showed inflammation in liver. Interestingly, LCA-induced necrosis, diffuse vacuolization and slight inflammatory cell infiltration in liver (Fig. 1g). These results suggested that LCA could directly cause liver cell damage beside of BAs regulation, but the specific mechanism still needs further the explore.

In the LCA-induced cholestatic liver injury model, bile acid homeostasis is imbalant in different bile acid poles. In serum, liver and bile, it is distinct that both conjugated and unconjugated BAs increased after the treatment of LCA. However, in intestine, especially jejunum, cecum and colon, the content of BAs had no obvious trends (Fig. 2g-k). This is because BAs were reabsorbed in the terminal ileum entering the liver through enterohepatic circulation. In serum and liver, almost elevated BAs could be reduced by OCA. It 
indicated there was antagonism between LCA and OCA which means their effect of BAs regulation was majorly involved a same pathway.

Studies have shown that FXR could inhibit the bile acid synthase CYP7A1 and CYP8B1, promote the expression of bile acid efflux transporter, reduce the expression of bile acid uptake transporter [22-24]. In this study, the way of OCA improving cholestasis was mainly based on increasing bile acid efflux transporter to promote bile excretion. Unexpectedly, as a matter of fact, bile acid synthase CYP7A1 and CYP8B1 were increased in this study (Fig. 4c-d). This phenomenon might be a result of BAs excreted to a physiological state after the treatment of OCA instead of the direct effect of OCA on FXR in liver.

It was reported that apoptosis and necroptosis played an important role in cholestatic liver injury[19, 25]. The main pathways of apoptosis are the death receptor-mediated exogenous apoptosis pathway and the mitochondrial-mediated endogenous apoptotic pathway. The exogenous apoptotic pathway is that the death ligand produced by natural killer cells or macrophages binds to the death receptor in the target membrane and then activates Caspase 8, thus leading to the activation of Caspase 3 and Caspase 7 and inducing apoptosis[26]. Activation of endogenous apoptotic pathway will lead to activation of Bax increasing the permeability of mitochondrial outer membrane, and then release Cytochrome $C$, which will bind to the apoptotic protein activator-1(Apaf-1), and then activate Caspase 9 [27]. Necroptosis is another way of cell death which charactered as a massive inflammatory response and increased phosphorylation of MLKL [28]. In this study, there was a inflammatory response in hepatocyte after the treatment of LCA, but p-MLKL had no significant change (Fig. 7d-e). It was suggested that necroptosis was not the major way in LCA modeling. Here, the inflammation might be a secondary response. Focus on apoptotic pathway, it was showed increased of cleaved Caspase-8 and -3 without change of Bax (Fig. 7b-C, 8c). OCA down-regulated the activation of Caspase $8 / 3$ which indicating OCA mainly resisted LCA-induced apoptosis via Caspase $8 / 3$ inhibition.

FXR has been recognized as a target for the treatment of viral hepatitis, alcohol-induced liver disease, non-alcoholic steatohepatitis, cholestasis and even hepatocellular carcinoma[29]. In recent study, it was found that FXR was an intrinsic apoptosis inhibitor in liver[30]. FXR could inhibit apoptotic signal transduction by associating with Caspase 8 in cytoplasm to prevent its recruitment into the deathinducing signaling complex[17]. In this study, OCA restored the expression of FXR enhancing the association of FXR and Caspase8 in cytoplasm to block apoptotic signal transduction induced by LCA. However, in $F X r^{\Delta L}$ model, the hepatotoxicity of LCA reduced significantly and OCA could not further decrease the expression of cleaved Caspase-8 (Fig. 7f). These results indicated that FXR activation is a necessary process for OCA resisting LCA-induced exogenous apoptosis in hepatocyte.

\section{Conclusions}

In summary, OCA regulated bile acid metabolism through increase the expressions of bile acid efflux transporter BSEP, MRP2, MRP3 and MDR3 in LCA-induced cholestatic liver injury. Besides, OCA activated FXR reducing Caspase 8 cleavage to form death-inducing signaling complex in nuclear which inhibit LCA- 
induced exogenous apoptosis. These results contributed a novel vision to understand the antihepatotoxic effect of OCA, which provided a new evidence for the usage of OCA in cholestatic liver injury.

\section{Methods}

\section{Chemical and Reagents}

LCA (purity $>97 \%$ ) was purchased from Aladdin Co., Ltd. (Shanghai, China). OCA (purity $>99 \%$ ) was purchased from Shanghai Hope-Chem Co., Ltd. (Shanghai, China). Trizol reagent, SYBR Green Master Mix and Reverse Transcription Kit for Q-PCR were purchased from Vazyme Biological Technology Co., Ltd. (Nanjing, China). Primers used for Q-PCR were purchased from Invitrogen Co., Ltd. (CA, USA).

Antibody against FXR(13194-1-AP) was purchased from Proteintech Group (NA,USA). Antibody against SHP (A1836) and $\beta$-actin (AC026) were purchased from ABclonal Technology Co.,Ltd. (Wuhan, China). Antibody against CYP7A1 (DF2612) and CYP8B1 (DF4762) were purchased from Affinity Biosciences(OH,USA). Antibody against MRP2(sc-59611), MDR3(sc-58221), and NTCP(sc-518115) were purchased from Santa Cruz Biotechnology, Inc. (CA,USA). Antibody against Cleaved Caspase-3 (9661), Cleaved Caspase-8 (8592), Cleaved PARP (9532), Bax (2772) and MRP3(39909) were purchased from Cell Signaling Technology Co., Ltd. (MA, USA). Antibody against p-MLKL (Ser345) (ab196436) and BSEP (ab155421) were purchased from Abcam Co., Ltd. (CA, USA).

\section{Animal treatment}

Male C57BL/6J mice (SPF grade) purchased from the Vital River Laboratory Animal Technology Co., Ltd. (Shanghai, China) were selected in this study. The animals were kept in the barrier system of Animal Experimental Center of China Pharmaceutical University (temperature $25 \pm 2^{\circ} \mathrm{C}$, humidity $50 \% \pm 5 \%$, $12 \mathrm{~h}: 12 \mathrm{~h}$ light-dark cycle). The mice were free to eat and drink. The experiment began after a week of adaptive feeding. Before the experiment, mice were stratified and randomly divided according to body weight. All experiments involving experimental animals were conducted under the guidance of animal ethics management system.

Mice were randomly divided into 5 groups including control group, LCA group, OCA $10 \mathrm{mg} / \mathrm{kg}$ group (LCA+OCA-L), OCA $20 \mathrm{mg} / \mathrm{kg}$ group (LCA+OCA-H) and OCA $20 \mathrm{mg} / \mathrm{kg}$ group. OCA was administered to mice (i.g.) for 7 days. Since the 4th day, mice received administration of LCA (i.g., $400 \mathrm{mg} / \mathrm{kg} / \mathrm{time}$, Bid) after OCA or vehicle treatment for 4 days. The body weight and food intake of mice were measured every day. Mice were fasted $12 \mathrm{~h}$ and sacrificed after the last LCA injection. Serum, liver, ileum and feces samples were collected and snap-frozen in liquid nitrogen, then storing at $-80^{\circ} \mathrm{C}$.

\section{Biochemical indicators determination}

Serum Alanine Aminotransferase (ALT), Aspartate Aminotransferase (AST) and Alkaline Phosphatase (ALP) were detected using kits from Weiteman Biotech Co., Ltd. (Nanjing, China). Serum Total Bile Acid 
(TBA) was detected using the kit from Jiancheng Bioengineering Institute (Nanjing, China). All kits were used according to the manufacturer's instructions.

\section{Liver Histopathological evaluations}

Liver tissues were fixed in $4 \%$ formaldehyde, embedded in paraffin and sectioned at $3 \mu \mathrm{m}$. Hematoxylin and eosin (HE) staining and immunohistochemistry $(\mathrm{IHC})$ of $\mathrm{p}-\mathrm{MLKL}$ were carried out to investigate the liver morphological changes, and necroptosis respectively.

\section{Terminal deoxynucleotidyl transferase-mediated labeling of nick-end DNA (TUNEL) staining}

Apoptosis was determined using the Fluorescein (FITC) Tunel Cell Apoptosis Detection Kit (Wuhan, China) according to the manufacturer's protocol.

\section{Caspase-3/7 activity assay}

To investigate apotosis in liver of cholestatic mice, we utilized the Apo-ONE Homogeneous Caspase-3/7 Assay (Promega, Mannheim, Germany). The liver tissues were split and the supernatant was collected by centrifugation. Mix the supernatant and caspase3/7 buffer at a ratio of 1:1 and perform follow-up tests under the guidance of the instructions.

\section{Determination of bile acid contents in serum, liver, bile and intestinal contents}

Tauroursodeoxycholic acid (TUDCA), taurohyodeoxycholic acid (THDCA), taurochenodeoxycholic acid (TCDCA), taurodeoxycholic acid (TDCA), taurocholic acid (TCA), taurolithocholic acid (TLCA), glycoursodeoxycholic acid (GUDCA), glycohyodeoxycholic acid (GHDCA), glycochenodeoxycholic acid (GCDCA), glycodeoxycholic acid (GDCA), glycocholic acid (GCA) and glycolithocholic acid (GLCA) were measured by LC-MS/MS. The mobile phase consisted of methanol $(\mathrm{MeOH} ;$ mobile phase $\mathrm{A})$ and $5 \mathrm{mM}$ ammonium acetate in aqueous solution containing $0.1 \%$ formic acid (mobile phase $B$ ) run at a flow rate of $0.1 \mathrm{ml} / \mathrm{min}$. The parameters and the LC gradient elution conditions were optimized as described before 30, 31. Surveyor LC pump and a Finnigan Surveyor autosampler in combination with a triple quadrupole TSQ Quantum mass spectrometer via electrospray ionization (ESI) interface (Thermo Fisher, Palo Alto, CA). Chromatographic separation was carried out using a Poroshell SB-C18 analytical column $(150 \times 3.0$ $\mathrm{mm}$, i.d., $2.7 \mu \mathrm{m})$. The column temperature was maintained at $35^{\circ} \mathrm{C}$, and the injection volume of each sample was $10 \mu \mathrm{L}$. Bile acids were detected in the negative mode. The ion source spray voltage was $3500 \mathrm{~V}$ and the transport capillary temperature was $400^{\circ} \mathrm{C}$.

\section{Liver specific FXR null mice}

Liver specific FXR null mice $\left(\mathrm{Fxr}^{\Delta \mathrm{L}}\right)$ were achieved from $\mathrm{Fxr}$ flox/flox $\left(\mathrm{Fxr} \mathrm{fl}^{\mathrm{fl} / \mathrm{f}}\right)$ mice and Alb-Cre genotyping mice purchased from Jiangsu Jicui Yaokang Biotechnology Co., Ltd. (Nanjing, China). Mice were randomly divided into 3 groups including control group, LCA group, OCA $10 \mathrm{mg} / \mathrm{kg}$ group. OCA was 
administered to mice (i.g.) for 7 days. Since the 4th day, mice received administration of LCA (i.g., 400 $\mathrm{mg} / \mathrm{kg} / \mathrm{time}, \mathrm{Bid}$ ) after OCA or vehicle treatment for 4 days.

\section{Cell culture and cell activity assay}

AML-12 (ATCC, CRL-2254) were cultured in DMEM/F12 at $37 \circ \mathrm{C}$ with 5\% CO2. DMEM/F12 were supplemented with $10 \%(\mathrm{v} / \mathrm{v})$ fetal bovine serum and $1 \%(\mathrm{v} / \mathrm{v})$ penicillin-streptomycin. AML-12 were seeded in 96-well plates at $2 \times 104$ cells/well. Cells were treated with $60 \mu \mathrm{M}$ LCA for $24 \mathrm{~h}$ with the pretreatment of $\operatorname{OCA}(1,5,10 \mu \mathrm{M})$ for 36 or $12 \mathrm{~h}$. $10 \%(\mathrm{v} / \mathrm{v})$ final concentration of Cell Counting Kit-8(CCK8) buffer was then added and the cell were further cultured for $4 \mathrm{~h}$ before measurement of absorbance at $450 \mathrm{~nm}$ using a microplate reader. Following experimental treatment, supernatant samples are transferred to a 96-well plate and an equal volume of CytoTox 96® Reagent(G1780) is added to each well and incubated for 30 minutes. Stop Solution is added, and the absorbance signal is measured at $490 \mathrm{~nm}$ in a plate reader. This assay was repeated three times.

\section{RNA extraction and real-time quantitative PCR}

Total RNA was extracted from mice liver or cell samples using TRIzol reagent. After quantitating the concentration of RNA with Nanodrop 2000 (Thermo, DE, USA), the same amount of RNA was reversed to CDNA. qPCR was performed using SYBR Green for target genes with specific primers on the ABI StepOnePlus Real-Time PCR (Thermo, DE, USA). The primers used in this study were listed on Table 1 and Gapdh was used for normalizing the quantity of cDNA. 
Table 1

\begin{tabular}{|c|c|c|}
\hline Gene & Primer orientation & Sequence $\left(5^{\prime}\right.$ to $\left.3^{\prime}\right)$ \\
\hline \multirow[t]{2}{*}{ Gapdh } & forward & CTTTGGCATTGTGGAAGGGCTC \\
\hline & reverse & GCAGGGATGATGTTCTGGGCAG \\
\hline \multirow[t]{2}{*}{ Tnf-a } & forward & GGTGCCTATGTCTCAGCCTCTT \\
\hline & reverse & GCCATAGAACTGATGAGAGGGAG \\
\hline \multirow[t]{2}{*}{ II-6 } & forward & TACCACTTCACAAGTCGGAGGC \\
\hline & reverse & CTGCAAGTGCATCATCGTTGTTC \\
\hline \multirow[t]{2}{*}{$I L-1 \beta$} & forward & TCGACCTTCCAGGATGAGGACA \\
\hline & reverse & GTTCATCTCGGAGCCTGTAGTG \\
\hline \multirow[t]{2}{*}{$\operatorname{Tgf}-\beta$} & forward & ACCAAGGAGACGGAATAC \\
\hline & reverse & TGTGGAGCTGAAGCAATA \\
\hline \multirow[t]{2}{*}{ Fxr } & forward & GGGATGAGTGTGAAGCCAGCTA \\
\hline & reverse & GTGGCTGAACTTGAGGAAACGG \\
\hline \multirow[t]{2}{*}{ Shp } & forward & CCAAGGAGTATGCGTACCTGAAG \\
\hline & reverse & GCTCCAAGACTTCACACAGTGC \\
\hline \multirow[t]{2}{*}{ Сур7а1 } & forward & САССАTTCCTGAAACСTTCTGG \\
\hline & reverse & ATGGCATTCCCTCCAGAGCTGA \\
\hline \multirow[t]{2}{*}{ Сур8b1 } & forward & CATGAAGGCTGTGCGTGAGGAA \\
\hline & reverse & CATCACGCTGTCCAACACTGGA \\
\hline \multirow[t]{2}{*}{ Bsep } & forward & CCTTGGTAGAGAAGAGGCGACA \\
\hline & reverse & ATGGCTACCCTTTGCTTCTGCC \\
\hline \multirow[t]{2}{*}{ Ntcp } & forward & СCTGATGCCTTTCACTGGCTTC \\
\hline & reverse & GGATGGTAGAACAGAGTTGGACG \\
\hline \multirow[t]{2}{*}{ Oatp2 } & forward & GGGTGAATGCCCAAGAGACA \\
\hline & reverse & TATAGCCTGCATGCTCCACG \\
\hline \multirow[t]{2}{*}{ Mrp2 } & forward & TACCAGCGAGTTATCGAAGCGTG \\
\hline & reverse & TGCTTCTGACCGCCACTGAGAT \\
\hline Mrp3 & forward & АCTTCCTCCGAAACTACGCACC \\
\hline
\end{tabular}

Page 10/25 


\begin{tabular}{|c|c|c|}
\hline Gene & Primer orientation & Sequence $\left(5^{\prime}\right.$ to $\left.3^{\prime}\right)$ \\
\hline & reverse & GCTGGCTCATTGTCTGTCAGGT \\
\hline \multirow[t]{2}{*}{ Bacs } & forward & CTACGCTGGCTGCATATAGATG \\
\hline & reverse & CCACAAAGGTCTCTGGAGGAT \\
\hline \multirow[t]{2}{*}{ Baat } & forward & GGAAACCTGTTAGTTCTCAGGC \\
\hline & reverse & GTGGACCCCCATATAGTCTCC \\
\hline \multirow[t]{2}{*}{ Сур3а11 } & forward & ACAAACAAGCAGGGATGGAC \\
\hline & reverse & GGTAGAGGAGCACCAAGCTG \\
\hline \multirow[t]{2}{*}{ Cyp2b10 } & forward & TCTGCCCTTCTCAACAGGAAA \\
\hline & reverse & GGAGTACTGATTTCCAGCAGGT \\
\hline \multirow[t]{2}{*}{ Gst1a1 } & forward & GCAGCATCAGAGAGAGAGAGATACC \\
\hline & reverse & CAACTGATCAGATAATGAACTAATACTTCTCC \\
\hline \multirow[t]{2}{*}{ Ugt2a3 } & forward & GCGAAACAACTTGAGGAGGCAC \\
\hline & reverse & TAATTGTCACTCAGGGCTTTCCC \\
\hline
\end{tabular}

\section{Western blot analysis}

Total protein was extracted from mice liver or cell samples using SDS buffer (Beyotime Biotechnology Co., Ltd., Shanghai, China). After quantitating the concentration of protein by BCA protein assay kit, the protein was then mixed with $4 \times$ loading buffer (Bio-Rad laboratories, CA, USA). Proteins were separated by SDS-PAGE and transferred onto polyvinylidene difluoride membranes. After blocking with $5 \%$ bovine serum albumin for one hour, the membranes were then incubated with primary antibody overnight at $4{ }^{\circ} \mathrm{C}$. The immunoblots were visualized with horseradish peroxidase-conjugated polyclonal secondary antibody using an ECL detection kit from Millipore (MA, USA).

\section{Statistical analysis}

The data in all experiment were expressed as means \pm SEM and analysis using GraphPad Prism 8 (GraphPad Software Inc., CA, USA). One-way analysis of variance (ANOVA) and two-way ANOVA followed by Tukey's Multiple Comparison Test were performed to analyze the differences between groups. $\mathrm{P}<0.05$ were considered to be statistically significant.

\section{Abbreviations}

OCA: obeticholic acid 
LCA: lithocholic acid

PBC: primary biliary cholangitis

ALT: alanine Aminotransferase

AST: aspartate Aminotransferase

ALP: alkaline Phosphatase

TBA: total Bile Acid

BSEP: bile salt export pump

MRP2: multidrug resistant associated protein 2

MRP3: multidrug resistant associated protein 3

MDR3: multi-drug resistance 3

NTCP: sodium taurocholate co-transporting polypeptide

OATP2: organic anion transporting polypeptide 2

FXR: farnesoid X receptor

DCA: deoxycholic acid

UDCA: ursodeoxycholic acid

HE: hematoxylin and eosin

IHC: immunohistochemistry

TUNEL: terminal deoxynucleotidyl transferase-mediated labeling of nick-end DNA

TUDCA: tauroursodeoxycholic acid

THDCA: taurohyodeoxycholic acid

TCDCA: taurochenodeoxycholic acid

TDCA: taurodeoxycholic acid

TCA: taurocholic acid

TLCA: taurolithocholic acid 
GUDCA: glycoursodeoxycholic acid

GHDCA: glycohyodeoxycholic acid

GCDCA: glycochenodeoxycholic acid

GDCA: glycodeoxycholic acid

GCA: glycocholic acid

GLCA: glycolithocholic acid

ESI: electrospray ionization

CCK-8: Cell Counting Kit-8

Tnf-a: tumor necrosis factor-a

IL-1ß: interleukin-1 $\beta$

II-6: interleukin-6

Tgf- $\beta$ : transforming growth factor $\beta$

\section{Declarations}

Ethics approval and consent to participate

Not applicable.

\section{Consent for publication}

All authors agree to publish this paper.

\section{Availability of data and materials}

The datasets used and/or analyzed during the current study are available from the corresponding author on reasonable request.

\section{Competing interests}

No potential conflict of interest was reported by the authors.

\section{Funding}

This study was supported by the National Natural Science Foundation of China (No.81773827), Scholar of the 14th batch of "Six Talents Peak" high-level talent selection (No.SWYY-094), "Double First-Class" 
University project (No. CPU2018GY33), the Postgraduate Research Practice Innovation Program of Jiangsu Province (No.KYCX19_0763) and Natural Science Foundation of Jiangsu Province (No.BK20210430).

\section{Authors' contributions}

ZZJ and QWY designed research; YPZ, CLW, YYM and YYC conducted research; JYY, and QWY analyzed and interpreted data;YPZ and QWY wrote the paper; ZZJ, QWY, YPZ, CLW, JYY, YYM and YYC reviewed the manuscript critically. None of the authors reported a conflict of interest related to the study. All authors read and approved the final manuscript

\section{Acknowledgements}

Not applicable.

\section{References}

1. M.D. Chow, Y.H. Lee, G.L. Guo, The role of bile acids in nonalcoholic fatty liver disease and nonalcoholic steatohepatitis, Mol Aspects Med 56 (2017) 34-44.

2. Y. Li, R. Tang, P.S.C. Leung, M.E. Gershwin, X. Ma, Bile acids and intestinal microbiota in autoimmune cholestatic liver diseases, Autoimmun Rev 16(9) (2017) 885-896.

3. C.D. Fuchs, G. Paumgartner, A. Wahlstrom, P. Schwabl, T. Reiberger, N. Leditznig, T. Stojakovic, N. Rohr-Udilova, P. Chiba, H.U. Marschall, M. Trauner, Metabolic preconditioning protects BSEP/ABCB11(-/-) mice against cholestatic liver injury, J Hepatol 66(1) (2017) 95-101.

4. T. Yang, T. Shu, G. Liu, H. Mei, X. Zhu, X. Huang, L. Zhang, Z. Jiang, Quantitative profiling of 19 bile acids in rat plasma, liver, bile and different intestinal section contents to investigate bile acid homeostasis and the application of temporal variation of endogenous bile acids, J Steroid Biochem Mol Biol 172 (2017) 69-78.

5. H. Zeng, Y. Jiang, P. Chen, X. Fan, D. Li, A. Liu, X. Ma, W. Xie, P. Liu, F.J. Gonzalez, M. Huang, H. Bi, Schisandrol $B$ protects against cholestatic liver injury through pregnane $\mathrm{X}$ receptors, $\mathrm{Br} \mathrm{J}$ Pharmacol 174(8) (2017) 672-688.

6. J.M. Ridlon, D.J. Kang, P.B. Hylemon, Bile salt biotransformations by human intestinal bacteria, Journal of lipid research 47(2) (2006) 241-59.

7. Y. Kong, X. Gao, C. Wang, C. Ning, K. Liu, Z. Liu, H. Sun, X. Ma, P. Sun, Q. Meng, Protective effects of yangonin from an edible botanical Kava against lithocholic acid-induced cholestasis and hepatotoxicity, Eur J Pharmacol 824 (2018) 64-71.

8. P. Fickert, A. Fuchsbichler, H.U. Marschall, M. Wagner, G. Zollner, R. Krause, K. Zatloukal, H. Jaeschke, $\mathrm{H}$. Denk, M. Trauner, Lithocholic acid feeding induces segmental bile duct obstruction and destructive cholangitis in mice, Am J Pathol 168(2) (2006) 410-22. 
9. L.D. Beilke, L.M. Aleksunes, E.R. Olson, D.G. Besselsen, C.D. Klaassen, K. Dvorak, N.J. Cherrington, Decreased apoptosis during CAR-mediated hepatoprotection against lithocholic acid-induced liver injury in mice, Toxicol Lett 188(1) (2009) 38-44.

10. Clinical Review Report: Obeticholic Acid (Ocaliva): (Intercept Pharmaceuticals Canada, Inc.): Indication: For the treatment of primary biliary cholangitis (PBC) in combination with ursodeoxycholic acid (UDCA) in adults with an inadequate response to UDCA or as monotherapy in adults unable to tolerate UDCA, Ottawa (ON), 2017.

11. D.G. Zhang, C. Zhang, J.X. Wang, B.W. Wang, H. Wang, Z.H. Zhang, Y.H. Chen, Y. Lu, L. Tao, J.Q. Wang, X. Chen, D.X. Xu, Obeticholic acid protects against carbon tetrachloride-induced acute liver injury and inflammation, Toxicol Appl Pharmacol 314 (2017) 39-47.

12. L. Vignozzi, A. Morelli, I. Cellai, S. Filippi, P. Comeglio, E. Sarchielli, E. Maneschi, G.B. Vannelli, L. Adorini, M. Maggi, Cardiopulmonary protective effects of the selective FXR agonist obeticholic acid in the rat model of monocrotaline-induced pulmonary hypertension, The Journal of Steroid Biochemistry and Molecular Biology 165 (2017) 277-292.

13. S. Fiorucci, E. Antonelli, G. Rizzo, B. Renga, A. Mencarelli, L. Riccardi, S. Orlandi, R. Pellicciari, A. Morelli, The nuclear receptor SHP mediates inhibition of hepatic stellate cells by FXR and protects against liver fibrosis, Gastroenterology 127(5) (2004) 1497-512.

14. H.L. Guo, H.M. Hassan, Y. Zhang, S.Z. Dong, P.P. Ding, T. Wang, L.X. Sun, L.Y. Zhang, Z.Z. Jiang, Pyrazinamide Induced Rat Cholestatic Liver Injury through Inhibition of FXR Regulatory Effect on Bile Acid Synthesis and Transport, Toxicol Sci 152(2) (2016) 417-28.

15. L. Verbeke, R. Farre, B. Verbinnen, K. Covens, T. Vanuytsel, J. Verhaegen, M. Komuta, T. Roskams, S. Chatterjee, P. Annaert, I. Vander Elst, P. Windmolders, J. Trebicka, F. Nevens, W. Laleman, The FXR agonist obeticholic acid prevents gut barrier dysfunction and bacterial translocation in cholestatic rats, Am J Pathol 185(2) (2015) 409-19.

16. X. Gao, T. Fu, C. Wang, C. Ning, K. Liu, Z. Liu, H. Sun, X. Ma, X. Huo, X. Yang, M. Zou, Q. Meng, Yangonin protects against cholestasis and hepatotoxity via activation of farnesoid $\mathrm{X}$ receptor in vivo and in vitro, Toxicol Appl Pharmacol 348 (2018) 105-116.

17. H. Wang, C. Ge, J. Zhou, Y. Guo, S. Cui, N. Huang, T. Yan, L. Cao, Y. Che, Q. Zheng, X. Zheng, F.J. Gonzalez, G. Wang, H. Hao, Noncanonical farnesoid $X$ receptor signaling inhibits apoptosis and impedes liver fibrosis, EBioMedicine 37 (2018) 322-333.

18. S.J. Yu, S. Bae, J.S. Kang, J.H. Yoon, E.J. Cho, J.H. Lee, Y.J. Kim, W.J. Lee, C.Y. Kim, H.S. Lee, Hepatoprotective effect of vitamin C on lithocholic acid-induced cholestatic liver injury in Gulo(-/-) mice, Eur J Pharmacol 762 (2015) 247-55.

19. M.B. Afonso, P.M. Rodrigues, A.L. Simao, D. Ofengeim, T. Carvalho, J.D. Amaral, M.M. Gaspar, H. Cortez-Pinto, R.E. Castro, J. Yuan, C.M. Rodrigues, Activation of necroptosis in human and experimental cholestasis, Cell Death Dis 7(9) (2016) e2390.

20. M. Funabashi, T.L. Grove, M. Wang, Y. Varma, M.E. McFadden, L.C. Brown, C. Guo, S. Higginbottom, S.C. Almo, M.A. Fischbach, A metabolic pathway for bile acid dehydroxylation by the gut microbiome, 
Nature 582(7813) (2020) 566-570.

21. P. Chen, H. Zeng, Y. Wang, X. Fan, C. Xu, R. Deng, X. Zhou, H. Bi, M. Huang, Low dose of oleanolic acid protects against lithocholic acid-induced cholestasis in mice: potential involvement of nuclear factorE2-related factor 2-mediated upregulation of multidrug resistance-associated proteins, Drug Metab Dispos 42(5) (2014) 844-52.

22. T. Li, L. Xu, R. Zheng, X. Wang, L. Li, H. Ji, Q. Hu, Picroside II protects against cholestatic liver injury possibly through activation of farnesoid X receptor, Phytomedicine 68 (2020) 153153.

23. J. Wang, T. Fu, R. Dong, C. Wang, K. Liu, H. Sun, X. Huo, X. Ma, X. Yang, Q. Meng, Hepatoprotection of auraptene from the peels of citrus fruits against 17alpha-ethinylestradiol-induced cholestasis in mice by activating farnesoid X receptor, Food Funct 10(7) (2019) 3839-3850.

24. D. Xiang, J. Yang, Y. Liu, W. He, S. Zhang, X. Li, C. Zhang, D. Liu, Calculus Bovis Sativus Improves Bile Acid Homeostasis via Farnesoid X Receptor-Mediated Signaling in Rats With Estrogen-Induced Cholestasis, Front Pharmacol 10 (2019) 48.

25. E. Hubel, A. Saroha, W.J. Park, Y. Pewzner-Jung, E.G. Lavoie, A.H. Futerman, R. Bruck, S. Fishman, J.A. Dranoff, O. Shibolet, I. Zvibel, Sortilin Deficiency Reduces Ductular Reaction, Hepatocyte Apoptosis, and Liver Fibrosis in Cholestatic-Induced Liver Injury, Am J Pathol 187(1) (2017) 122-133.

26. J.H. Kim, S.Y. Lee, S.Y. Oh, S.I. Han, H.G. Park, M.A. Yoo, H.S. Kang, Methyl jasmonate induces apoptosis through induction of Bax/Bcl-XS and activation of caspase-3 via ROS production in A549 cells, Oncology reports 12(6) (2004) 1233-8.

27. M.S. D'Arcy, Cell death: a review of the major forms of apoptosis, necrosis and autophagy, Cell Biol Int 43(6) (2019) 582-592.

28. A. Degterev, Z. Huang, M. Boyce, Y. Li, P. Jagtap, N. Mizushima, G.D. Cuny, T.J. Mitchison, M.A. Moskowitz, J. Yuan, Chemical inhibitor of nonapoptotic cell death with therapeutic potential for ischemic brain injury, Nat Chem Biol 1(2) (2005) 112-9.

29. H. Wang, Q. He, G. Wang, X. Xu, H. Hao, FXR modulators for enterohepatic and metabolic diseases, Expert Opin Ther Pat 28(11) (2018) 765-782.

30. Z. Gai, T. Gui, I. Alecu, M.A. Lone, T. Hornemann, Q. Chen, M. Visentin, C. Hiller, S. Hausler, G.A. KullakUblick, Farnesoid $X$ receptor activation induces the degradation of hepatotoxic 1-deoxysphingolipids in non-alcoholic fatty liver disease, Liver international : official journal of the International Association for the Study of the Liver 40(4) (2020) 844-859.

\section{Figures}


Fig. 1

a

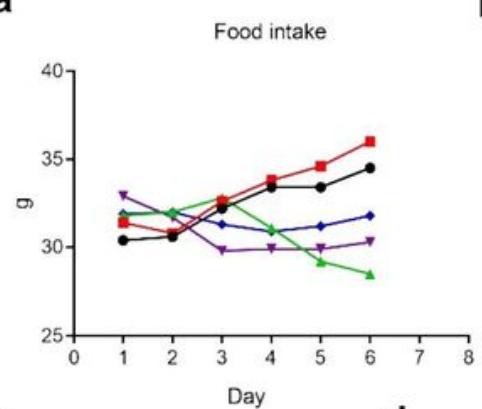

b

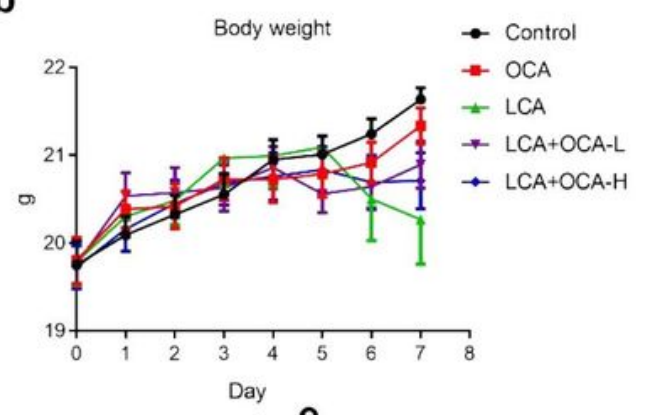

C

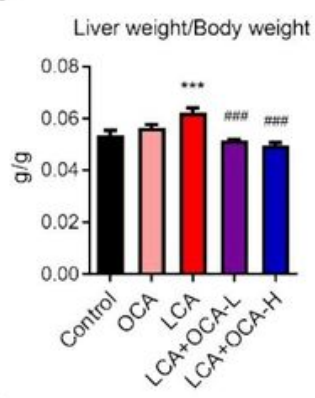

g

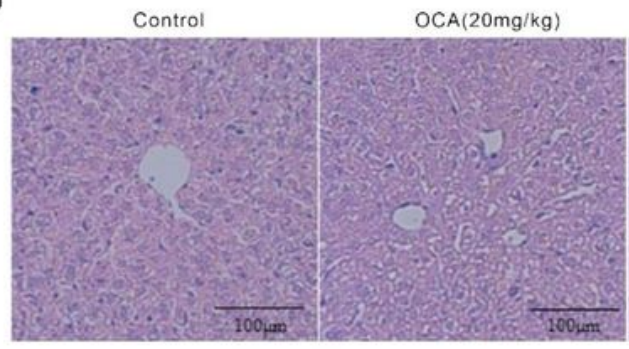

h

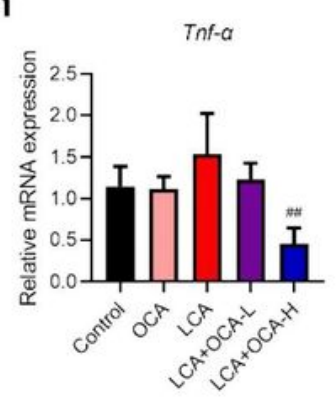

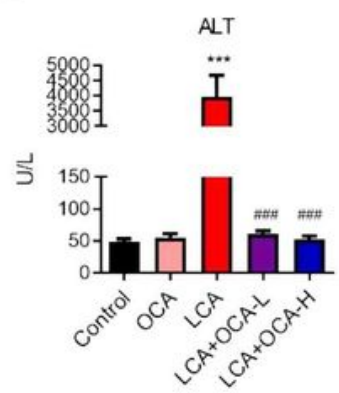

I

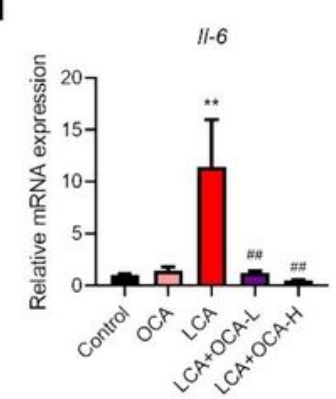

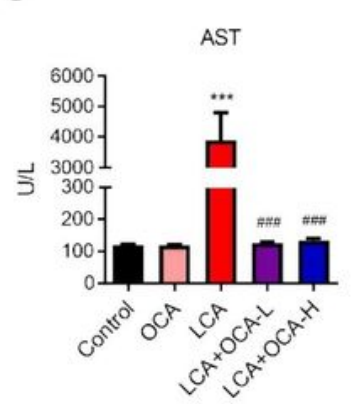

f

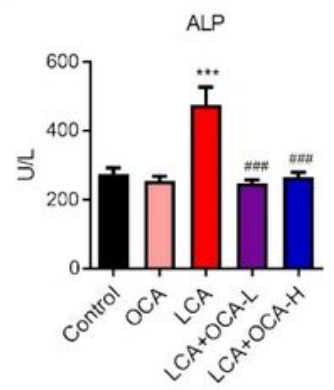

LCA

LCA + OCA $-\mathrm{L}$

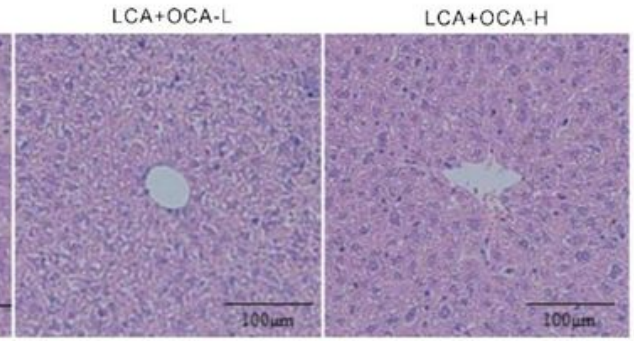

j

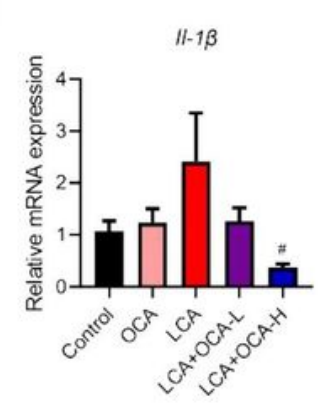

k

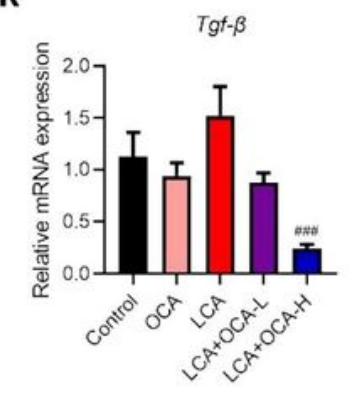

\section{Figure 1}

Hepatoprotective effects of OCA against LCA-induced liver injury. (A) Time-depended changes in food intake in mice. (B) Time-depended changes in body weight in mice. (C) Changes of Liver weight/Body weight in mice. (D) ALT, (E) AST, (F) ALP activity in mice. (G) H\&E staining of liver in mice (100x). The mRNA expressions of $(H)$ Tnf- $a,(I) ~ I I-6,(J) ~ I l-1 \beta,(K)$ Tgf- $\beta$ in mice compared to house-keeping gene 
Gapdh. Date were Mean \pm SEM $(n=12) .{ }^{*} P<0.01,{ }^{*} * x<0.001$ versus the control group. $\# P<0.05$, $\# \# P<0.01, \# \# \# P<0.001$ versus the LCA group.

Fig. 2

a
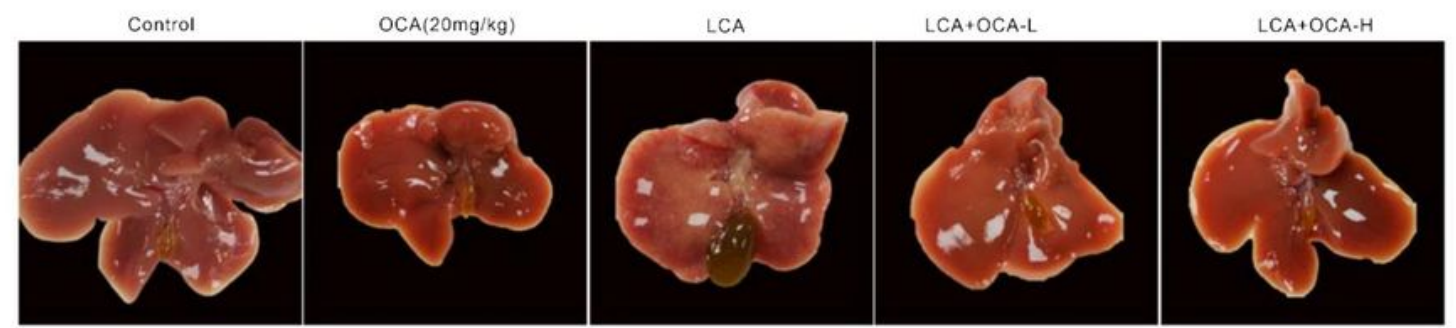

b
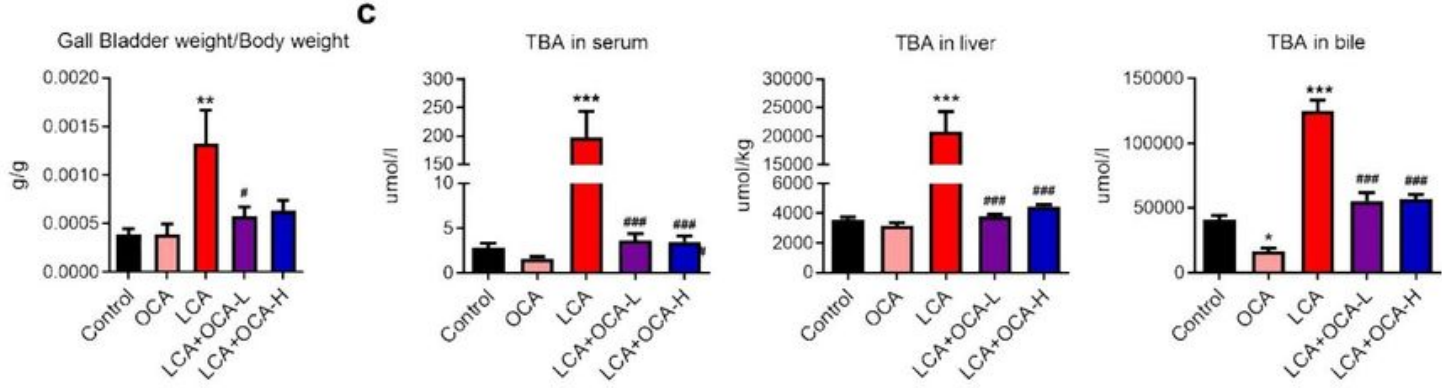

d

e

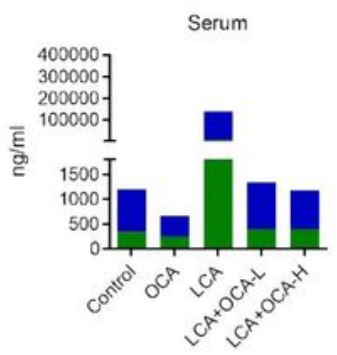

h

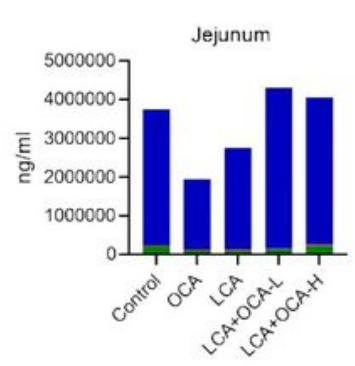

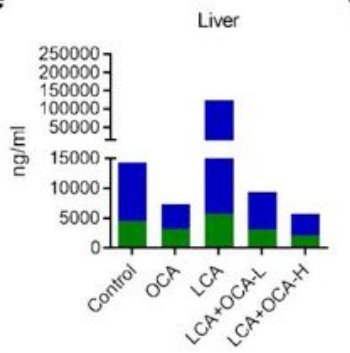

I

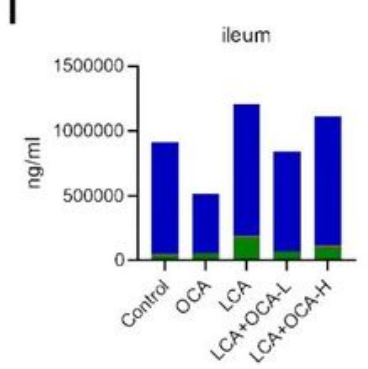

f

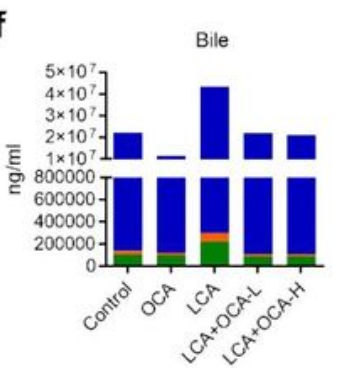

j

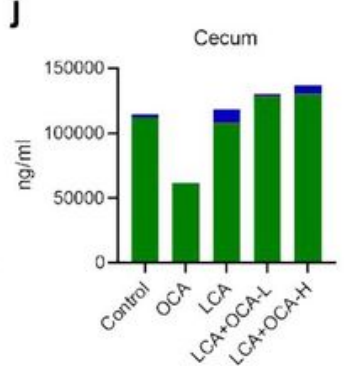

g

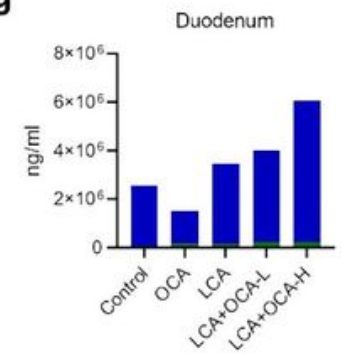

k

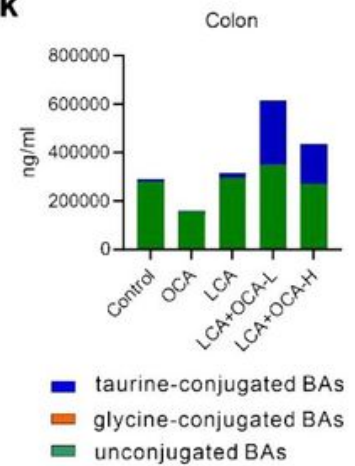

Figure 2

OCA improved LCA-induced cholestasis in mice. (A) Morphology of liver in mice. (B) Changes of Gall bladders weight/Body weight in mice. (C) Changes of TBA in serum, liver and bile. The content of bile acids in (D) serum, (E) liver, $(F)$ bile, $(G)$ duodenum, $(H)$ jejunum, $(I)$ ileum, $(J)$ cecum and $(K)$ colon. Date 
were Mean $\pm \operatorname{SEM}(n=12) .{ }^{*} P<0.01,{ }^{* \star \star} P<0.001$ versus the control group. $\# P<0.05, \# \# \# P<0.001$ versus the LCA group.

Fig. 3

a

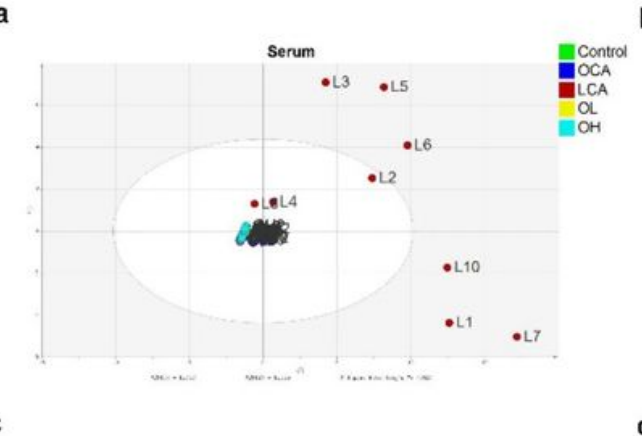

c

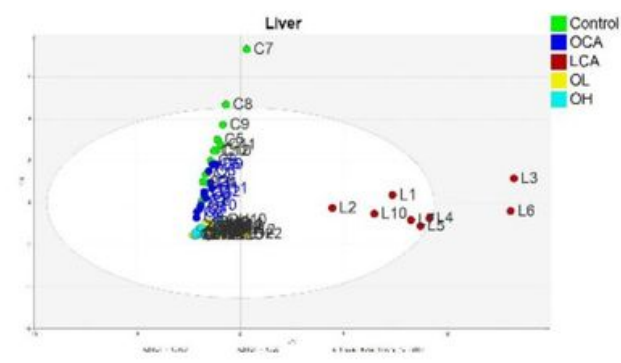

e

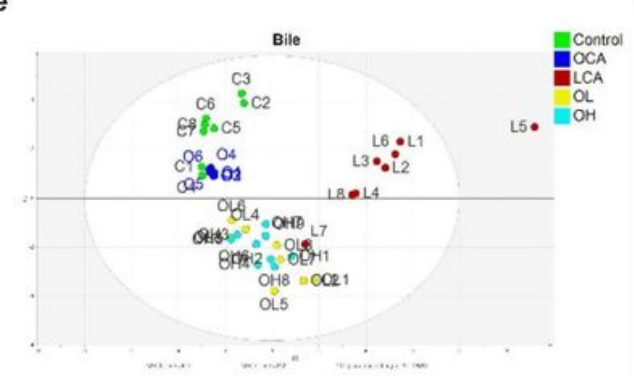

b
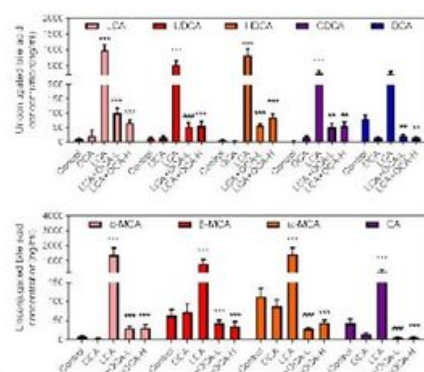

d

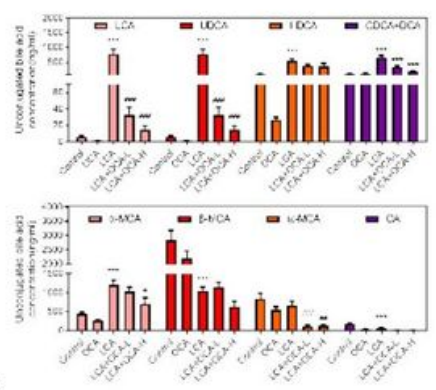

f

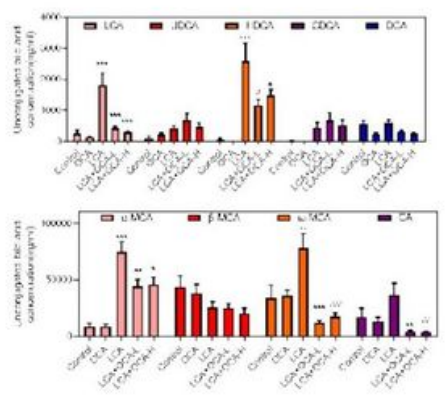

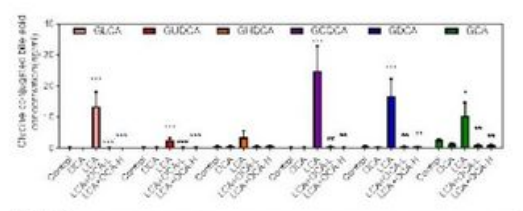
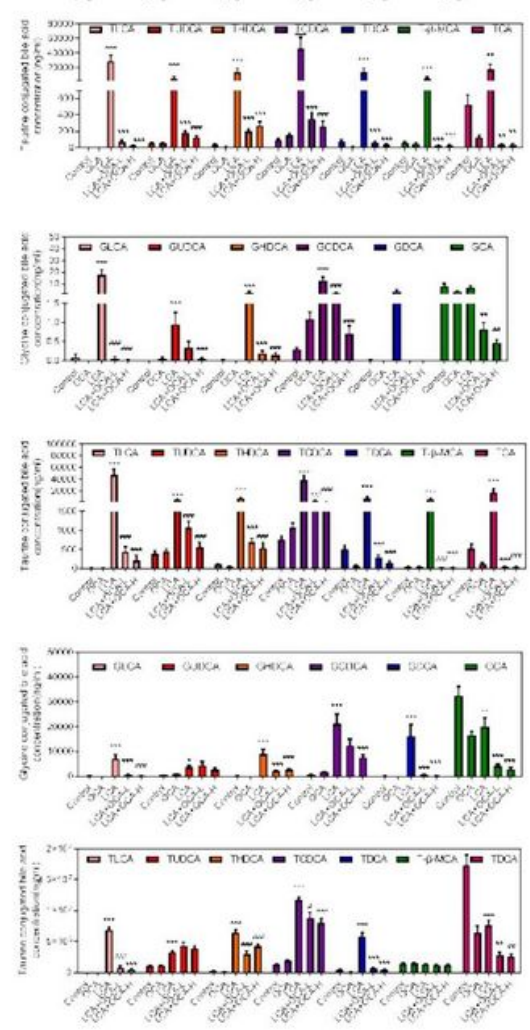

\section{Figure 3}

OCA altered bile acids profile of serum, liver and bile in LCA-induced cholestatic mice. PCA analysis in (A) serum, (C) liver and (E) bile. 22 kinds of bile acid concentration in (B) serum, (D) liver and (F) bile. Date are Mean \pm SEM $(n \geq 6) .{ }^{*} P<0.05,{ }^{*} P<0.01,{ }^{*} * * P<0.001$ versus the control group. $\# P<0.05, \# \# P<0.01$, $\# \# \# \mathbf{P}<0.001$ versus the LCA group. 
Fig. 4

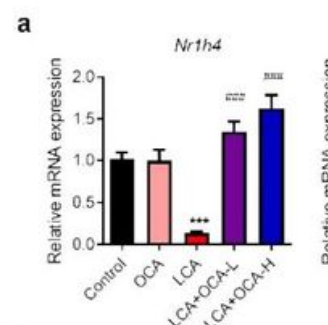

c
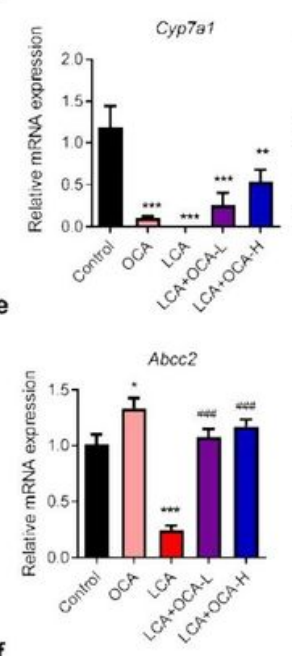

f

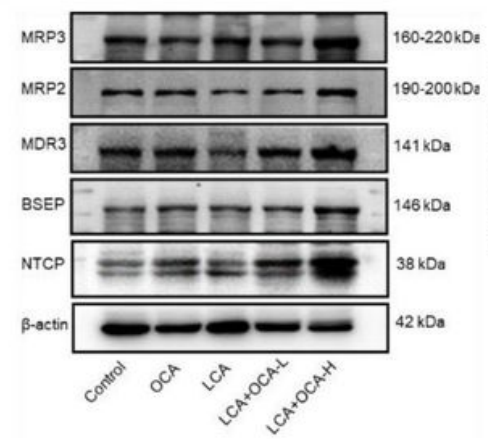

b
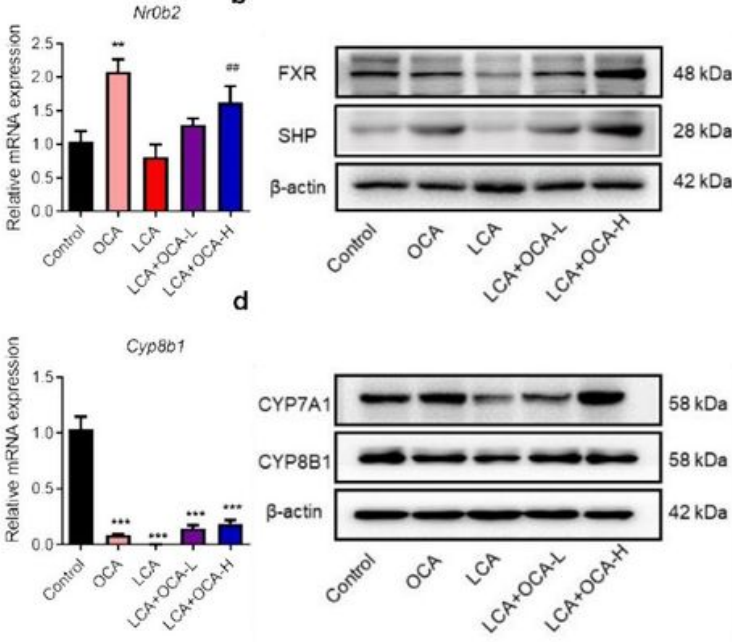

$A D C C 3$
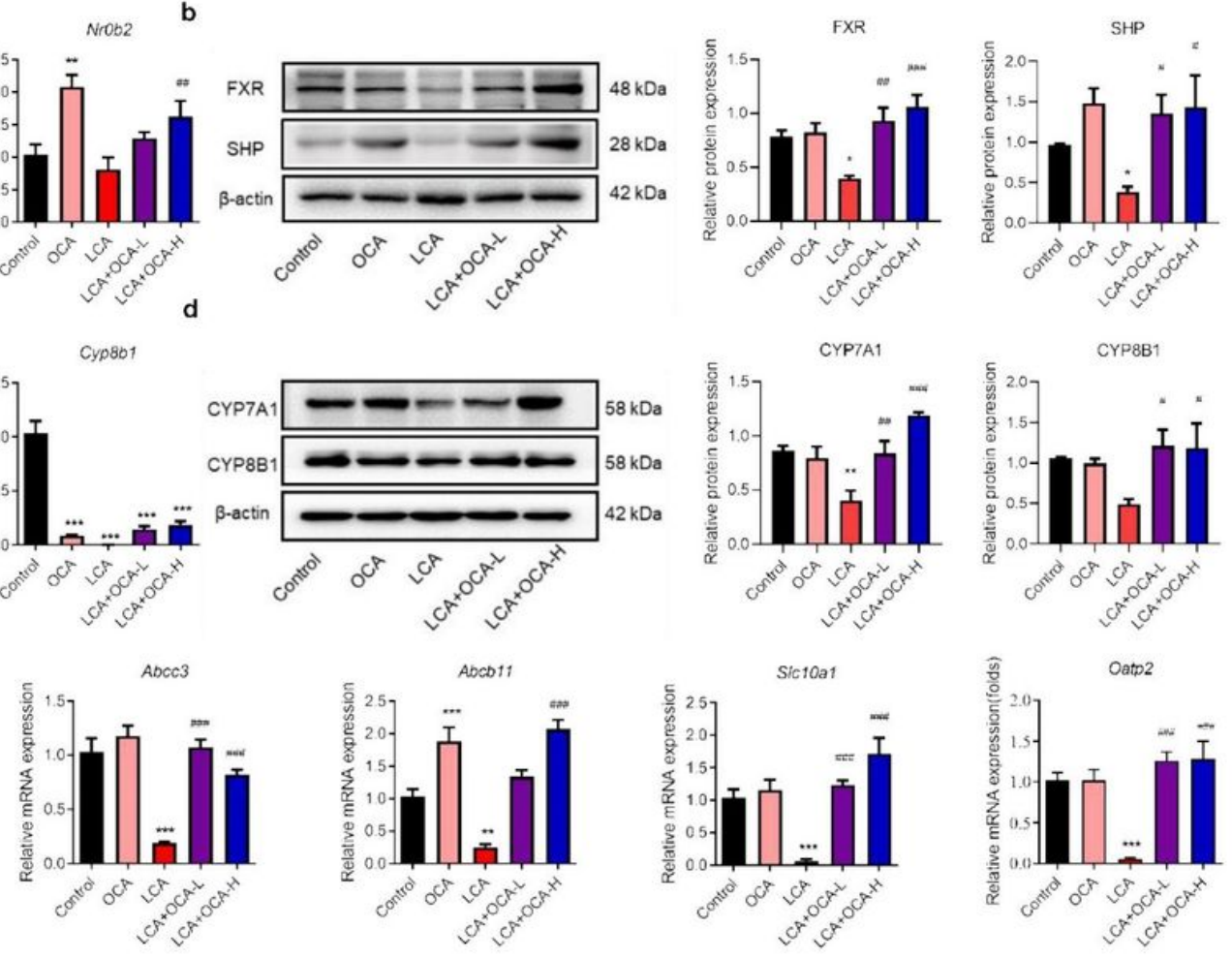

BSEP
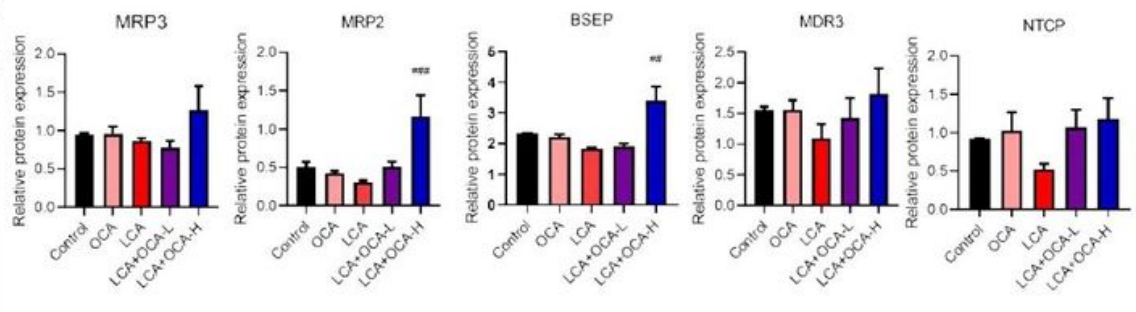

NTCP

\section{Figure 4}

OCA activated FXR to resisted LCA-induced cholestasis in vivo. The mRNA expression of (A) Nr1h4, NrOb2 (C) Cyp7a1, Cyp8b1 (E) Abcc2, Abcc3, Abcb11, Slc10a1, Oatp2 in mice liver. The protein expression of (B) FXR, SHP (D) CYP7A1, CYP8B1 (F) MRP3, MRP2, MDR3, BSEP and NTCP in mice liver. Specific band intensity was quantified, normalized to $\beta$-actin. Date are Mean \pm SEM $(n=12) .{ }^{*}<<0.05,{ }^{\star} P<<0.01$,

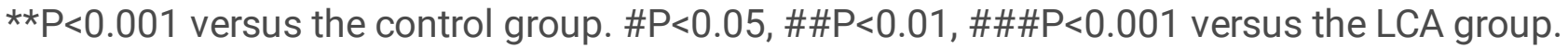


Fig. 5

a
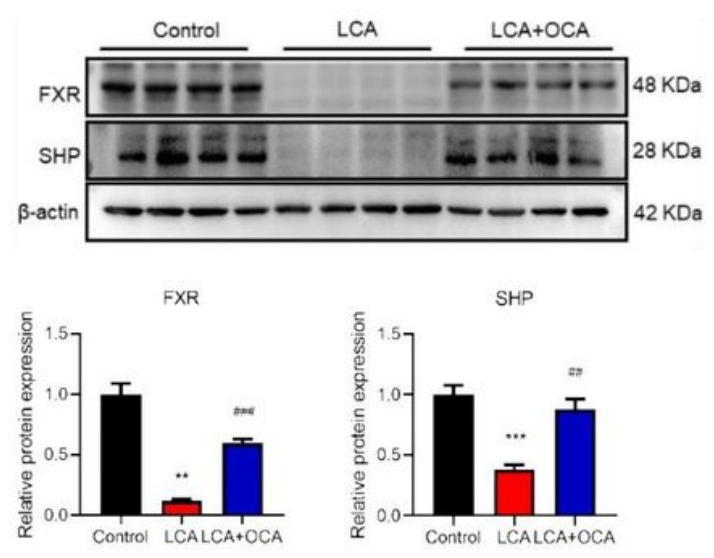

b
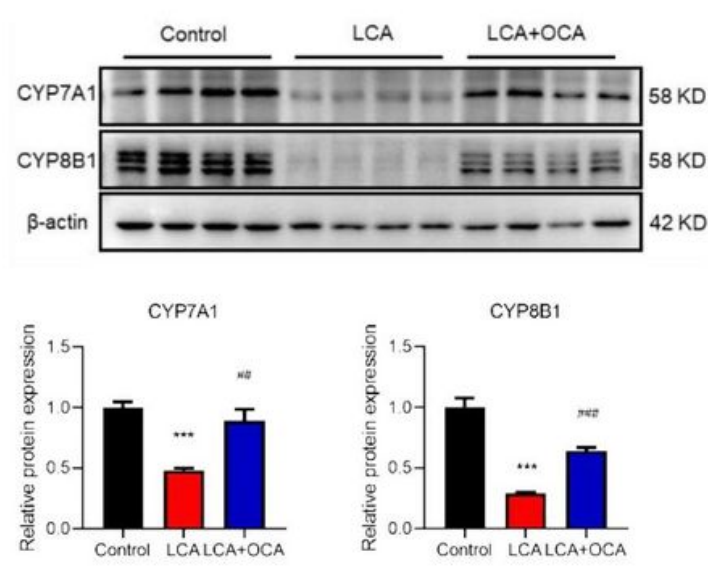

c
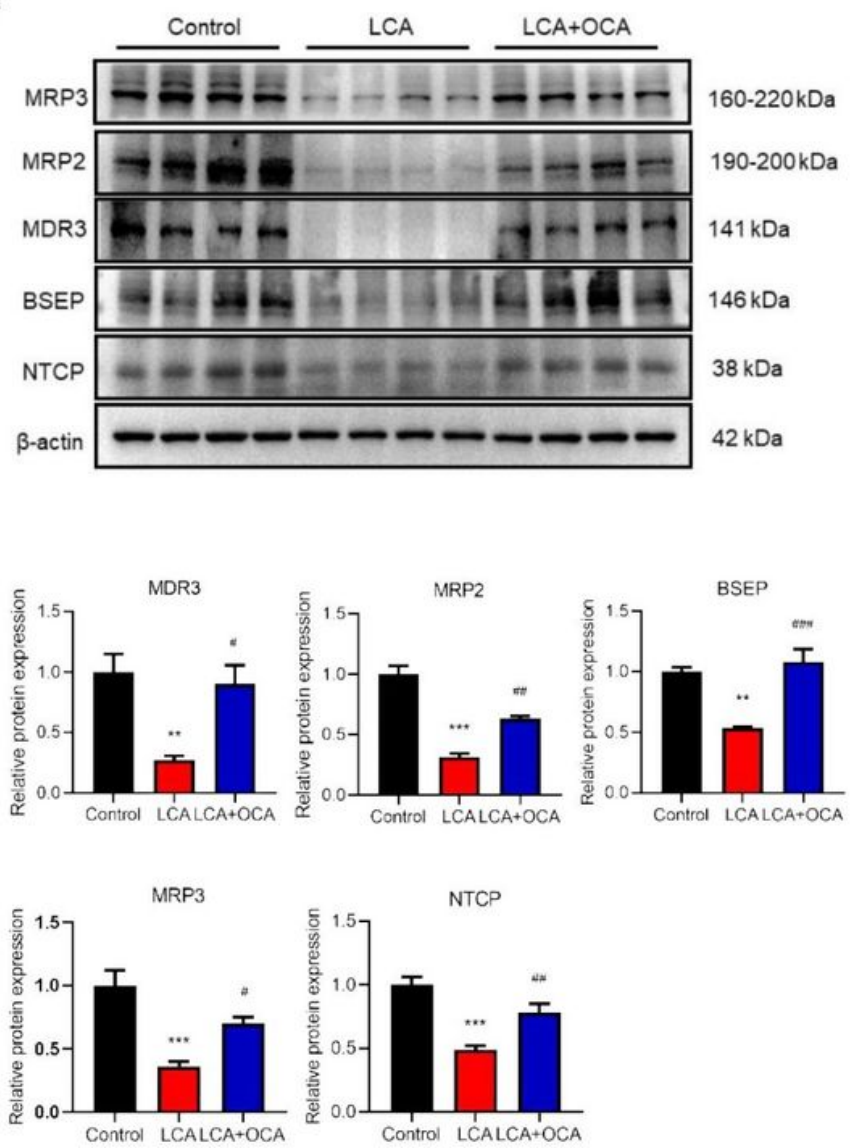

\section{Figure 5}

OCA activated FXR to resisted LCA-induced cholestasis in vitro. The protein expression of (A) FXR, SHP (B) CYP7A1, CYP8B1 (C) MRP3, MRP2, MDR3, BSEP and NTCP in AML-12. Specific band intensity was quantified, normalized to $\beta$-actin. Date are Mean $\pm \operatorname{SEM}(n=3) .{ }^{*} P<0.01,{ }^{\star}{ }^{*} \mathrm{P}<0.001$, versus the control group. \#P<0.05, \#\#P<0.01, \#\#\#P<0.001 versus the LCA group. 
Fig. 6

a

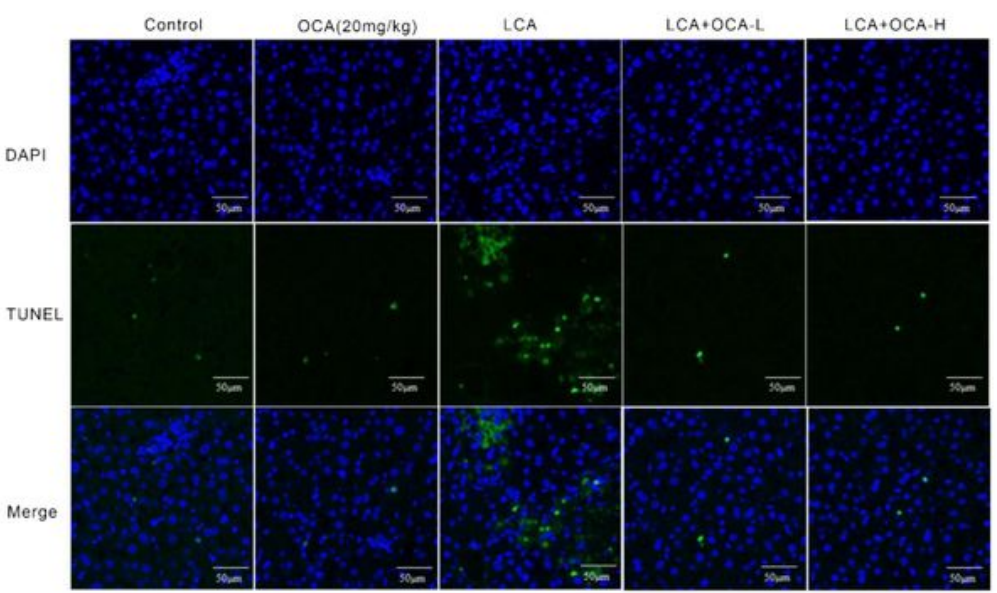

b
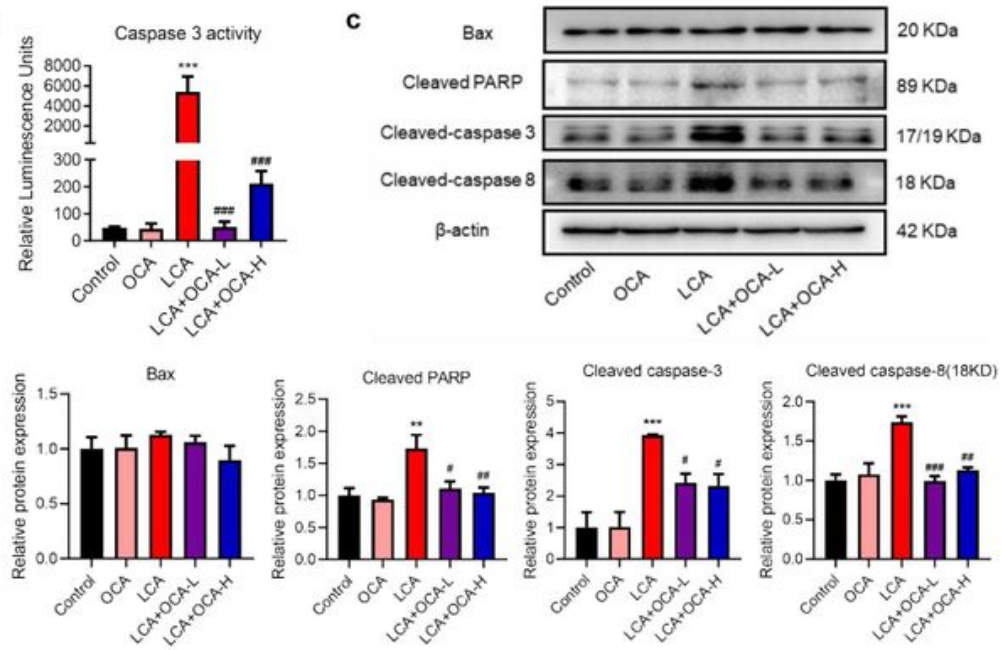

d

Control OCA $(20 \mathrm{mg} / \mathrm{kg})$ LCA LCA+OCA.L LCA $+O C A \cdot H$
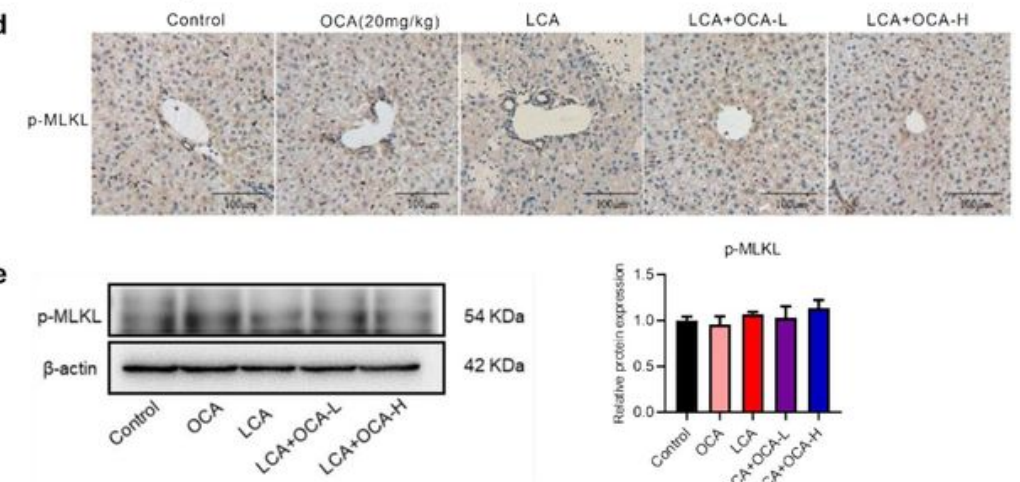

p-MLKL.

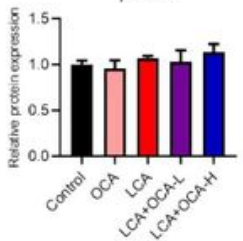

Figure 6

OCA inhibited LCA-induced hepatocyte exogenous apoptosis in vivo. (A) TUNEL staining of liver in mice (200x). (B) Caspase 3 activity in liver of C57BL6 mice. (C) The protein expression of BAX, cleaved PARP, cleaved Caspase-3, and cleaved Caspase-8 in mice liver. Specific band intensity was quantified, normalized to $\beta$-actin. (D) IHC staining of p-MLKL (100x) in mice liver. (E) The protein expression of $p$ MLKL in mice liver. Specific band intensity was quantified, normalized to $\beta$-actin. Date are Mean \pm SEM 
$(n=12) .{ }^{*} P<0.01,{ }^{\star} * * P<0.001$, versus the control group. $\# P<0.05, \# \# P<0.01, \# \# \# P<0.001$ versus the LCA group.

Fig. 7

a

b

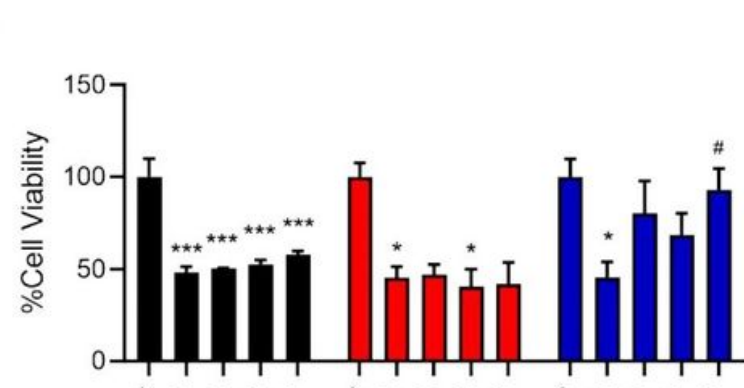

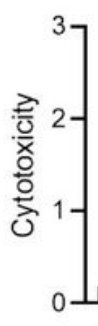

- $3 \mathrm{~h}$
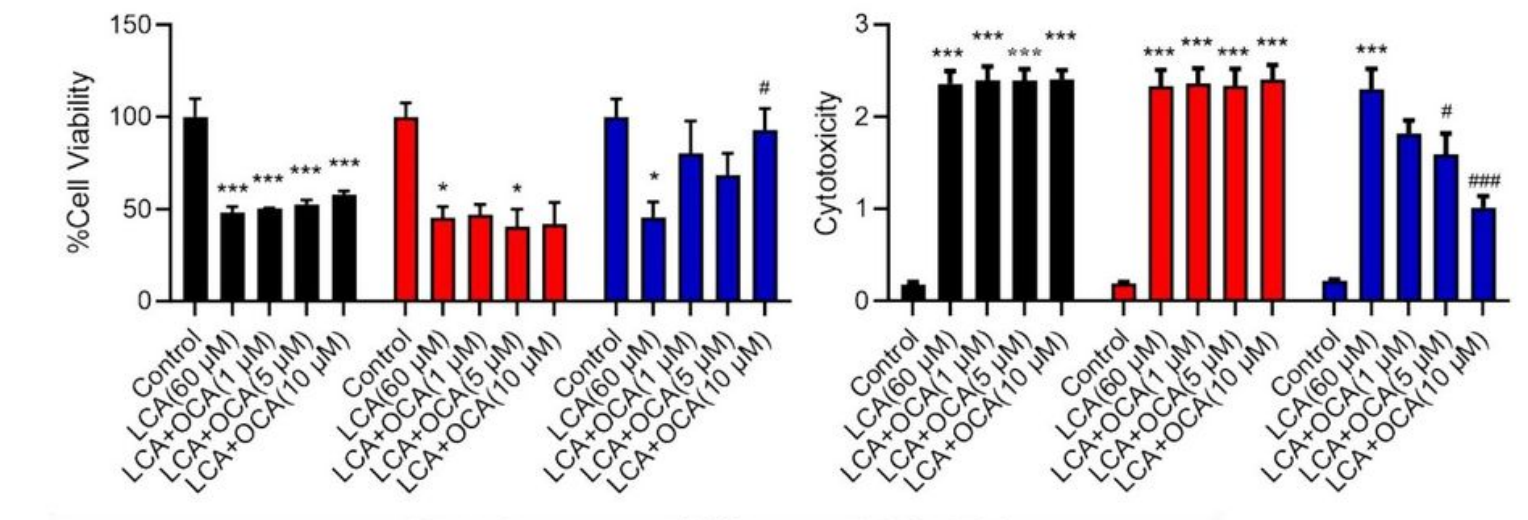

$\square 6 \mathrm{~h}$

- $12 \mathrm{~h}$
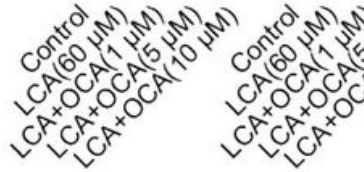

$\sim x^{x}+x^{x}$

vicip

C

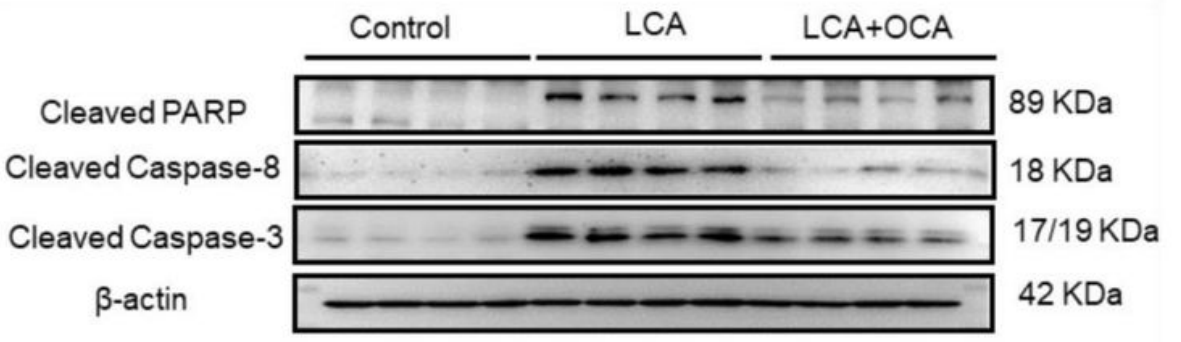

Cleaved PARP

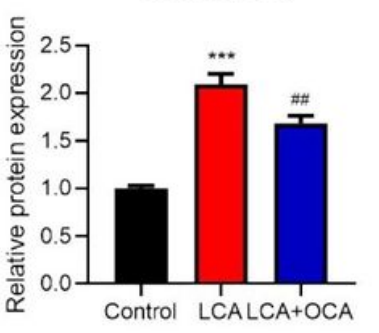

Cleaved caspase-8(18KD)

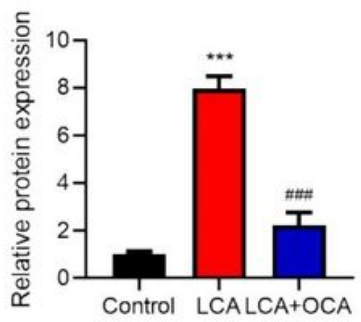

Cleaved Caspase-3

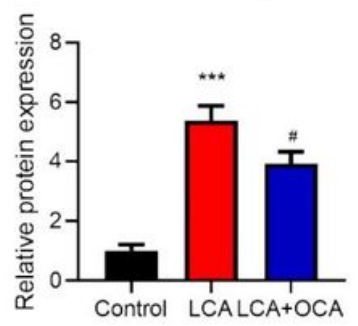

Figure 7

OCA inhibited LCA-induced hepatocyte exogenous apoptosis in vitro. (A) CCK8 and (B) LDH were used to detect the cell viability and cytotoxicity. (C) The protein expression of BAX, cleaved PARP, cleaved Caspase-3 and cleaved Caspase-8 in AML12. Specific band intensity was quantified, normalized to $\beta$ actin. Date are Mean $\pm S E M(n=3) .{ }^{\star} P<0.05,{ }^{\star \star \star} P<<0.001$, versus the control group. $\# P<0.05, \# \# P<0.01$, $\# \# \#<0.001$ versus the LCA group. 
Fig. 8

a

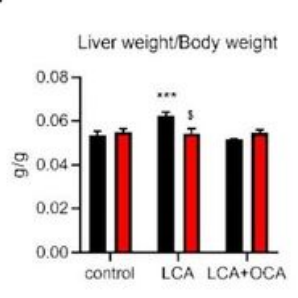

c

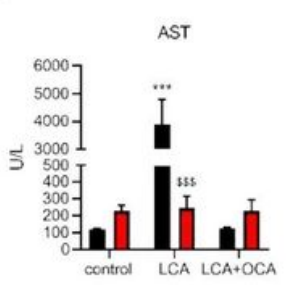

b

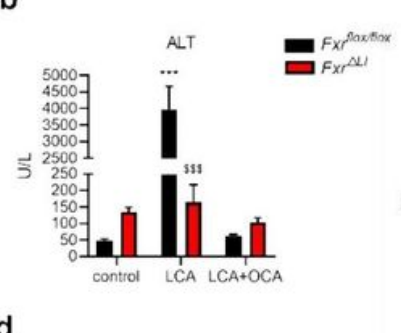

e
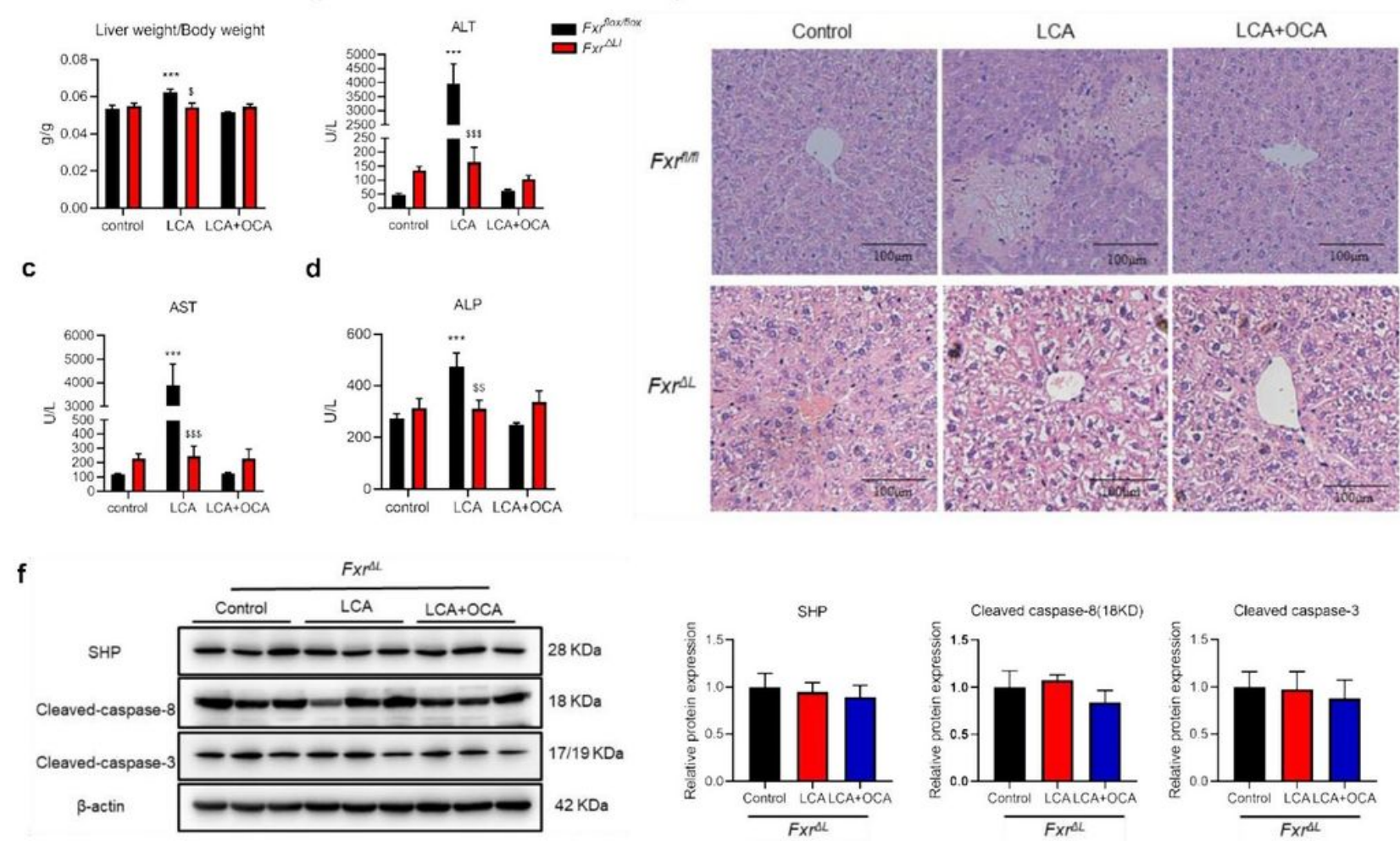
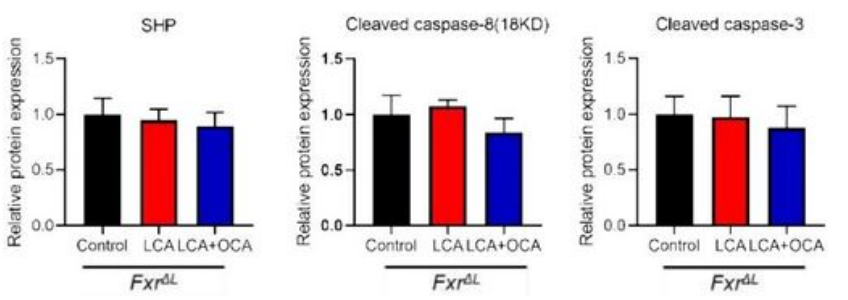

\section{Figure 8}

OCA activated FXR to inhibit Caspase 8 cleavage in LCA-induced cholestatic liver injury. (A) Liver weight/Body weight index in Fxrfl/fl and Fxr $\Delta$ L mice. (B) ALT, (C) AST, (D) ALP activity in Fxrfl/fl and Fxr $\Delta \mathrm{L}$ mice. (E) H\&E staining of liver in Fxrfl/fl and Fxr $\Delta \mathrm{L}$ mice (100x). (F) The protein expression of SHP, cleaved Caspase-3 and cleaved Caspase-8 in Fxrfl/fl and Fxr $\Delta \mathrm{L}$ mice. Specific band intensity was quantified, normalized to $\beta$-actin. Date are Mean $\pm \operatorname{SEM}(n=6) .{ }^{\star} P<0.05,{ }^{\star} * \star P<0.001$, versus the control group.

$$
P<0.01
$$

$\$ P<0.001$ versus Fxrfl/f mice.

\section{Supplementary Files}

This is a list of supplementary files associated with this preprint. Click to download.

- FigS1.jpg 
- FigS2.jpg

- supplementarymaterial.pdf 